\title{
A COACHING PROGRAM FOR RECENTLY LICENSED YOUNG DRIVERS IN THE NETHERLANDS: WHICH DRIVERS ARE ATTRACTED?
}

\author{
Erik Roelofs $^{1}$, Jan Vissers ${ }^{2}$ \& Marieke van Onna ${ }^{1}$ \\ ${ }^{1}$ Cito, National Institute for Educational Measurement, The Netherlands \\ ${ }^{2}$ Royal Haskoning DHV, Amersfoort, The Netherlands \\ Email: Erik.Roelofs@cito.nl
}

\begin{abstract}
Summary: In line with European developments, a Dutch second phase coaching program was developed for young novice drivers to counteract their high accident risk. In this paper the design principles of the program are described. The empirical study focused on the entry characteristics of the participating young drivers $(n=3117)$ as compared to a reference group of young drivers $(n=345)$. Results show that the DX program attracted young drivers that in some respects showed a more risky profile than average young drivers in terms of speed violations, anger and the number of fines. In addition, four groups of participants with sharply differing driving styles could be distinguished.
\end{abstract}

\section{INTRODUCTION}

\section{Second phase driver training}

In order to counteract the high accident risk of young novice drivers during their first year of solo driving, several European countries have introduced so called second phase training programs, aimed at (young) drivers who have just acquired their driving license. It has been emphasized that these programs should concentrate on driving style variables, i.e. the way that young people choose to drive (Elander, West and French, 1993). Helman, Grayson and Parkes (2010) mention style variables that are associated with collision risk: speed choice, close following, high-risk overtaking, violation of traffic laws, driving anger, and engaging in distracting activities, such as texting and phoning. Also, factors located on the lifestyle level appear to be associated with collision risk: fatigue-related factors, alcohol use, overconfidence, sensation seeking, and boredom. The readiness and ability to take these factors into consideration when driving require higher order skills, among which self-reflection and awareness of emotions (Hatakka, et al., 2002). Recent studies show that training aimed at these skills does counteract the factors that cause young drivers' crash involvement (e.g. Isner et al., 2009; Gatscha and Brandstaetter, 2008).

Regarding the preferable approach it is stressed that higher order skills development should involve forms of driver coaching. According to recent insights (Bartl, et al., 2010) driver coaching puts the learner in an active role, encourages the learner to accomplish personal goals, and raises awareness and responsibility of the learner regarding his values, attitudes, knowledge, skills and habits. Coaching is expected to stimulate a sustainable learning process, by supporting cognitive and affective self-regulation on the part of the learner (Winne and Hadwin, 1998).

However, a challenge for the coaches is to deal with differences in learner entry characteristics that are predictive for subsequent learning: prior knowledge, past performance, degree of self- 
regulation, and motivation (Boekaerts, 1999; Boekaerts \& Cascallar, 2006; Hattie, 2009;). For instance, in school settings it is generally found that learners who participate in learning activities on the basis of instrinsic motivation or on internalized forms of extrinsic motivation use stronger self-regulation strategies during the learning process than learners with unclear motives ('amotivation') or extrinsic motives (Deci and Ryan, 2000). These very strategies (goal setting, planning, monitoring progress and evaluation) are known to contribute to active involvement in learning processes and subsequent positive outcomes.

\section{The Dutch second phase coaching program 'Drive Xperience'}

The current study focused on a Dutch second phase coaching program, the Drive Xperience', developed as part of a EU-project on the evaluation of post-license training for novice drivers.

The design principles of the DX- program were drawn from different sources of research. First, throughout the program it is emphasized that driving style is affected by decisions on higher level tasks (Hatakka et al, 2002). These include life tasks, e.g. socializing with peers, and strategic tasks, e.g. route decisions. Second, in the DX-program it is emphasized that drivers need to reflect on their own decisions, actions and consequences regarding driving. Third, in line with their poor calibrating performance (Fuller, 2005) young drivers are supported to maintain a safe balance between their own level of proficiency and the complexity of the traffic situations they engage in. Fourth, as the ultimate goal of the coaching program is improvement of driving quality, coaches are encouraged to address five inter-related criteria of driving performance (Roelofs, et al., 2010): 1) Driving safely; 2) Facilitating the traffic flow; 3) Consideration with other road users’ interests; 4) Smooth vehicle control 5) Environmentally-responsible driving.

As part of the program, participants complete two web-based assessments some weeks before the start of the coaching day: The Driver Risk Assessment (DRA) and the Driver Self-Assessment (DSA). These assessments result in individual driver profiles, which are used to determine personalized learning goals at the start of the day.

The actual driver coaching day consists of three parts:

(1) Coached trip, of which the main objective is to deliver feedback to the drivers about their driving performance.

(2) Track experience, of which the main objective is for participants to experience the limits of their skills in vehicle control and to share these experiences with other participants.

(3) Group discussion, of which the main objective is to stimulate recognition of potentially risk factors in everyday driving situations, such as alcohol use and speed choice.

In this study, attention was focused on the entry characteristics of participating young drivers, which make up the conditions under which driver coaches deliver their coaching. The following research questions were addressed:

(1) What are the driving characteristics of young drivers enrolled in the DX-program (DX participants) in terms of their driving history, their personal risk factors, and their selfperceptions regarding driving performance? Do DX participants differ from the average young Dutch driver on these driving characteristics? 
(2) Are there any recognizable sub groups of DX- participants that differ from each other in terms of driving characteristics?

(3) How are participants motivated to take part in the DX-program? How does the type of motivation (intrinsic, extrinsic, amotivation) relate to driving characteristics?

\section{METHOD}

\section{Data collection}

Data from the DRA and DSA were used to investigate the research questions. The DRA is a 119 item web-based questionnaire regarding the driver's history and behavioral risk factors. Driving history pertains to years of driving experience, mileage, types of traffic situations to which the driver is exposed, the number of active and passive accidents he was involved in during the past year and the number of fines received the past year. Questions regarding behavioral risk factors pertain to speed choice, lane preference on motorways, alcohol use and driving, anger towards others participants, distraction and fatigue. Most of the questions are Likert type items.

The DSA is a web-based questionnaire consisting of 45 illustrated questions. It comprises a selfassessment of driving performance addressing the five performance criteria of driving described above. Each question is accompanied by a picture, showing the essential features of the traffic situation to which the question refers. Participants respond by using a four-point Likert-scale.

To assess young drivers' motives for participation, an adapted version of the Situational Motivation Scale (SIMS, Guay, Vallerand \& Blanchard, 2000), a 16 item questionnaire, was administered to a sub sample of 174 participants on seven randomly chosen coaching days. The questionnaire results in scores for amotivation, extrinsic motivation and intrinsic motivation.

\section{Participants}

Data from young drivers enrolled on the DX-coaching program (referred to as 'DX group') were used. The DX group ( $n=3117)$ participated in a total of 110 training groups, distributed across 66 municipalities. Participants had been recruited by a personal invitation from the mayor.

Advertisements were placed in local newspapers, and participants could register on a website, which supplied additional information on the program.

The training programs involved took place in the period between August 2010 and November 2012 and enrolled 1651 male and 1466 female participants. The participants, aged between 18 and 24 years, had held their driving license for about one year. Their average mileage amounted to 7274 kilometers, which is somewhat less than the mileage of the average Dutch young driver. The sub sample of 174 participants was representative for the whole DX-group in terms of the background variables described above.

To enable comparison with a reference group of young drivers (referred to as 'YD-Ref group') several analyses were performed on a database containing data from a large-scale survey that used representative samples of the Dutch population. This survey had been carried out almost 
yearly since 1990 (Eversdijk et al., 2000) until 2005. For purposes of comparison only the 2005 were used $(n=345)$, since traffic safety figures had changed considerably since 1990.

\section{RESULTS}

Table 1 shows the average number of accidents per one million kilometers. Since the data concerned frequency data on a fixed number of kilometers that were skewed to the right, a Poisson model was appropriate for testing the null-hypothesis that the active accident rates (driver at fault) in the DX group and the YD-ref group are equal. This hypothesis was not rejected $(\chi 2=0.06, d f=1, p=.86)$. The two groups did not differ in their active accident risk.

Similar results were found for the passive accidents rate (driver not at fault). The two young driver groups did not differ significantly $(\chi 2=0.06, d f=1, p=.06)$. Finally, the DX group had a significantly higher fine rate than the YD-Ref group $(\chi 2=2158, d f=1, p=.86, p<.001)$.

Table 1. Mileage and average number of accidents per million kilometers

\begin{tabular}{lcccc}
\hline Group and age & Mileage & $\begin{array}{l}\text { Active } \\
\text { accidents }\end{array}$ & $\begin{array}{l}\text { Passive } \\
\text { accidents }\end{array}$ & Fines \\
\hline DX group $(\mathrm{n}=2060)$ & 7,274 & 22.0 & 11.0 & 71.7 \\
YD-Ref group $(\mathrm{n}=345)$ & 9,785 & 21.9 & 11.4 & 48.6 \\
\hline
\end{tabular}

Table 2 shows results regarding behavioral risk factors. DX participants reported that they rather often drive in risky traffic situations: during rush hour and weekend nights, on roads outside built-up areas, and in town centers. In addition, they reported that they sometimes extensively use alcohol (mean .38). However, they reported that they seldom combine extensive alcohol use with driving. This is reflected by the low score on the scale 'use of adversary alcohol strategies' (mean: $=.06$ ), referring to questions about adversary strategies to minimize the effects of alcohol once participants had taken alcohol, e.g. drink a cup of strong coffee before driving home.

A next risk factor, loss of concentration, rarely occurred to DX participants (mean: $=.10$ ). This scale referred to unconscious and distracted driving (E.g. cell phone use). The anger subscales referred to the driver's reaction on other road users' violations or deviating driving behavior. In terms of anger DX participants very often reacted calmly (mean: $=.74$ ) but also rather often with withheld anger (mean $=.57)$. Irritated reactions towards other participants occurred occasionally $($ mean $=.19)$. Seriously angry reactions occurred rarely (mean: $=.03)$.

Table 2. Self-reported behavior regarding risk factors

\begin{tabular}{|c|c|c|c|c|}
\hline & \multicolumn{2}{|c|}{$\begin{array}{r}\text { DX group } \\
(n=2060)\end{array}$} & \multicolumn{2}{|c|}{$\begin{array}{c}\text { YD-ref Group } \\
(n=345)\end{array}$} \\
\hline & $\mathbf{M}$ & SD & $\mathbf{M}$ & SD \\
\hline Exposure to various risky traffic situations ( 5 items, $\alpha=.78$ ) & 0.52 & 0.22 & - & - \\
\hline Extensive alcohol use (2 items, $\alpha=.66$ ) & 0.38 & 0.23 & - & - \\
\hline Adversary alcohol strategies (11 items, $\alpha=.93$ ) & 0.06 & 0.18 & - & - \\
\hline Concentration loss (13 items, $\alpha=.81$ ) & 0.10 & 0.08 & - & - \\
\hline Seriously angry towards other road users ( 2 items, $\alpha=.51$ ) & 0.03 & 0.14 & .01 & .13 \\
\hline Irritated towards others ( 4 items, $\alpha=.63$ ) & 0.19 & 0.27 & .13 & .23 \\
\hline Withholds anger towards others ( 4 items, $\alpha=.59$ ) & 0.57 & 0.30 & .43 & .26 \\
\hline Stays calm towards others ( 2 items, $\alpha=.48$ ) & 0.74 & 0.35 & - & - \\
\hline Violation speed limits under various circumstances (9 items, $\alpha=.92$ ) & 0.14 & 0.13 & - & - \\
\hline Violation speed limits under favorable circumstances ( 3 items, $\alpha=.65$ ) & 0.23 & 0.17 & .20 & .19 \\
\hline Driving on outer lanes (5 items, $\alpha=.75$ ) & 0.33 & 0.24 & - & - \\
\hline Fatigue during driving ( 5 items, $\alpha=.70$ ) & 0.09 & 0.10 & - & - \\
\hline
\end{tabular}


Available data from the young driver reference group showed that average young drivers reacted less frequently with irritation $(t=4.4, d f=2992, p<.001)$, withheld anger $(t=9.2, d f=2992, p$ $<.001)$ and serious anger $(t=2.5, d f=2992 ; p<.05)$ than the DX participants.

A fourth risk factor pertained to speed choice and lane preference. On average, DX participants claimed that they rarely violate the limits under average circumstances (mean $=.14$ ) and occasionally under favorable (mean: .23) circumstances. DX participants reported that they sometimes prefer to drive on the outer lanes on the motorways (mean: $=.33$ ). Finally, on average DX participants rarely experienced fatigue while driving (mean: $=.09$ ).

Table 3 shows results for the Driver Self-Assessment. The first scale consisted of 14 items addressing errors that affect traffic safety (e.g. following too close), traffic flow (e.g. causing others to wait), and vehicle control (e.g. errors when using gears). On average, DX participants reported that they occasionally commit errors (mean: $=.18$ ) that affect these criteria.

The second scale, 'driving in a hurry' referred to the tendency to drive faster than the speed limits and to get irritated by those who drive slower than that. DX drivers reported that they sometimes drive in a hurry (mean: $=.44$ ). The overall scale 'Perceived own driving proficiency' (45 items) covers the degree to which the driver reported a safe, flow-aiding, social, controlled and environmentally considerate way of driving. On average, DX drivers reported that they often show this driving behavior (mean: $=.74)$.

Table 3. driving proficiency reported by the DX-group $(n=2924)$ on the Driver Self-Assessment

\begin{tabular}{lll}
\hline & SD & M \\
\hline Committing driving errors $(14$ items, $\alpha=.77)$ & .10 \\
Driving in a hurry $(6$ items, $\alpha=.74)$ & .18 & .44 \\
Perceived own driving proficiency $*(45$ items, $\alpha=.83)$ & .74 \\
\hline Note: $0 .-.16$ : rarely; $.17-.33:$ occasionally; .34-.50: sometimes; .51-.67: rather often; .68-0.84: very often; .85-.1 most of the times; $*$ & .81 \\
Negatively formulated items reversed &
\end{tabular}

174 participants reported about their motives to participate through the SIMS questionnaire. On average the participants took part out of rather strong intrinsic motives (see Table 4; items referred to statements as "it seems interesting”, "it seems fun”, "it was my own decision”). Also extrinsic motivation, in the form of internalized motives offered from outside was reported (E.g. “it gives a good feeling; it's for my own good; it is important to learn”). To a far lesser degree participants reported extrinsic motivation in the form of conformation to outside pressure ("I had no choice; I had the feeling I had to"). To a little higher degree participants reported motives that reflect amotivation (“I don’t know if I go on with this, I don’t know why I participate”).

Table 4. Motivation of a representative sub sample of participants $(n=174)$

\begin{tabular}{lll}
\hline & M & SD \\
\hline Intrinsic motivation (4 items, $\alpha=.79)$ & 5.67 & 0.82 \\
Extrinsic motivation: internalized motives offered from outside (4 items, $\alpha=.81)$ & 5.10 & 0.99 \\
Extrinsic motivation: conforming to outside pressure (5 items. $\alpha=.79)$ & 2.31 & 1.14 \\
Amotivation (3 items, $\alpha=.63$ ) & 2.73 & 1.07 \\
\hline Note: Likert-scale per item: $1=$ [the motive] does not apply to me; 4: applies reasonably to me; 7= applies totally to me
\end{tabular}

Correlations between the scores on the four motivation scales and the reported driving characteristics yielded the following picture (see Table 5). To the extent that participants scored higher on the internalized form of extrinsic motivation, they tended to drive less hurried, violated speed limits less frequently, drove less frequently on outer lanes, and reported in general a higher perceived proficient driving behavior. Opposite relationships for proficiency self-image, speed violations and hurried driving were observed for the degree in which participants show 
amotivation. Intrinsic motivation correlated positively with driving proficiency and negatively with committing driving errors. Conforming to outside pressure correlated positively with committing of driving errors and negatively with overall driving proficiency.

Table 5. Correlations between Motivation and some driving characteristics

\begin{tabular}{lcccc}
\hline & Amotivation & $\begin{array}{c}\text { Extrinsic motivation: } \\
\text { outside pressure }\end{array}$ & $\begin{array}{c}\text { Extrinsic motivation: } \\
\text { internalized motives }\end{array}$ & $\begin{array}{c}\text { Intrinsic } \\
\text { motivation }\end{array}$ \\
\hline Committing driving errors & .15 & $.19^{*}$ & .09 & $-.19^{*}$ \\
Driving in a hurry & $.19^{*}$ & .04 & $-.29^{* *}$ & -.12 \\
Perceived own driving proficiency & $-.32^{* *}$ & $-.27^{* *}$ & $.26^{* *}$ & $.32^{* *}$ \\
Violation speed limits under & $.19^{*}$ & .08 & $-.37^{* *}$ & -.13 \\
$\quad$ various circumstances & .11 & .00 & $-.24^{* *}$ & -.03 \\
Driving on outer lanes & & & & \\
\hline
\end{tabular}

Finally, hierarchical cluster analyses on the driving characteristics identified four sharply distinct clusters of participants. The biggest cluster reflected the average DX-participant (71\%), as described above. One small cluster (1\%) represented 'fast and aggressive' drivers who find themselves rather often on outer lanes and who drive in a hurry most of the times, but who at the same time do not consider themselves as erratic drivers. Both their relative accident risk and their number of fines were two times higher than that of the average DX-participant. Another cluster represented 'erratic and fast' drivers (4\%), who report that they sometimes commit driving errors. Their relative accident risk and number of fines were comparable to that of the 'fast and aggressive drivers'. A final cluster represented 'rule following calm drivers' (25\%). They reported that they obeyed speed limits, kept concentrated during driving and reacted calmly towards deviating drivers.

\section{CONCLUSIONS}

Looking at their entry characteristics, DX- participants in general showed a somewhat less favorable driving style than the average young (Dutch) driver. In terms of their relative accident risk, they were comparable to the average young driver. However, their number of fines was higher, they reported more frequently irritation towards other drivers, and they committed more driving errors and violations of speed limits than average young drivers.

The analyses showed that DX-participants do not form one homogeneous group of young drivers. Next to a large group that fits into the picture described above, three other groups could be distinguished. The largest of them represented drivers who always obey speed limits, show low accident rates, and in general stay calm towards other road users. Next, there were two relatively small groups that have very unfavorable driving characteristics. They had been more frequently involved in crashes than average, collected many more fines, and reported more often unfavorable driving behaviors regarding speed and aggression. These two latter groups differed in their self-image. One group reported own erratic behavior, while the other group hardly did. In general, participants showed either strong instrinsic motives or internalized motives offered from outside to take part, which make up a positive condition for subsequent learning. However, some participants started from unclear motives or from outside pressure (e.g. forced by parents). We found that unclear motives paralleled with unfavorable driving styles, whereas intrinsic motivation or internalized motives were related to more favorable driving styles.

All in all, the group heterogeneity in terms of past driving performance and driving characteristics was considerable within the analyzed period of two years. Although the DX- 
program provides opportunities to confront young drivers with their self-image and driving behavior, successful implementation depends on the quality of the coaches and their ability to accommodate for learner differences. Therefore, in a follow-up study attention will be paid to the coaching process, as it took place and how it affected reflective processes, self-regulation, and changes in attitudes and driving behavior on the part of the young drivers.

\section{REFERENCES}

Bartl, G., et al. (2010). High impact approach for Enhancing Road safety through More Effective communication Skills In the context of category B driver training. EU HERMES Project Final Report.

Boekaerts, M. (1999). Self-regulated learning: where we are today. International Journal of Educational Research, 31(6), 445457.

Boekaerts, M., \& Cascallar, E. (2006). How far have we moved toward the integration of theory and practice in self-regulation? Educational Psychology Review, 18(3), 199-210.

Deci, E. L., \& Ryan, R. M. (2000). The 'what' and 'why' of goal pursuits: Human needs and the self-determination of behavior. Psychological Inquiry, 11(4), 227-268.

Elander J., et al. (1993). Behavioural correlates of individual differences in road traffic crash risk: an examination of methods and findings. Psychological Bulletin, 113 (2) 279-294.

Eversdijk, J.J.C., et al. (2000). PROV 1999 Periodiek Regionaal Onderzoek Verkeersveiligheid [PROV 1999: periodic Dutch regional research into traffic safety]. Report number: TT00-66. Veenendaal: Traffic Test BV.

Fuller, R., (2005). Towards a general theory of driver behaviour. Accident Analysis and Prevention, 37, 461-472.

Gatscha, M., and Brandstaetter, C., (2008) Evaluation der zweiten Ausbildungsphase in Österreich [Evaluation of the second phase system in Austria]. Forschungsarbeiten aus dem Verkehrswesen. Vol. 173. Austrian Federal Ministry of Transport, Innovation and Technology. Vienna, Austria.

Guay, F., Vallerand, R. J., \& Blanchard, C. (2000). On the assessment of situational intrinsic and extrinsic motivation: the situational motivation scale (SIMS). Motivation and Emotion, 24(3), 175-213.

Hatakka, M., et al. (2002) From control of the vehicle to personal self-control; broadening the perspectives to driver education. Transportation Research Part F, 5, 201-215.

Hattie J (2009) Visible Learning: a synthesis of over 800 meta-analyses relating to achievement London; Routledge.

Helman, S., et al. (2010). A review of the effects of experience, training and limiting exposure on the collision risk of new drivers. TRL Insight Report INS005. Bracknell (UK): Transport Research Laboratory.

Roelofs, E.C., at al. (2010). Development of the Driver Performance Assessment: Informing Learner Drivers of their Driving Progress. In L. Dorn (Ed.) Driver behavior and training, volume IV (pp. 37-50). Hampshire: Ashgate Publishing Limited.

Winne, P.H., and Hadwin, A.F., (1998). Studying as self-regulated learning. In D.J. Hacker, J. Dunlosky, \& A.C. Graesser (Eds.), Metacognition in educational theory and practice (pp. 277-304). Hillsdale, NJ: Erlbaum. 